\title{
Factors Impacting the Effectiveness of the ISO 9000 Quality Management System of HCMC-Based Enterprises
}

\author{
NGUYẼ̃N QUANG THU \\ University of Economics HCMC \\ Email:ng-thu@yahoo.com \\ NGÔ THỊ ÁNH \\ University of Economics HCMC \\ Email: anhnt@ueh.edu.vn
}

\section{ARTICLE INFO}

Received:

March 20, 2013

Received in revised form

March 29, 2013

Accepted:

June 15, 2013

Keywords:

factors

efficiency

quality management

ISO 9000

enterprises

\section{ABSTRACT}

This aims to investigate factors influencing the effectiveness of the ISO 9000 quality management system of HCMC-based enterprises. There are 210 respondents who are workers and managers of HCMCbased companies using ISO 9000. Measurement scales are established upon seven factors: (1) managers' commitments, (2) roles of middle managers, (3) participation of employees, (4) internal information system, (5) collaboration of customers and providers, (6) professional consultants, and (7) quality management documents. Research findings indicate that the variable "roles of middle managers" should be left out and the remainders, save for "quality management documents", have impacts on the effectiveness of the ISO 9000 quality management system. Additionally, some suggestions are also extended to enterprises which have employed or plan to employ ISO 9000 to boost the efficiency of their quality management system. 


\section{INTRODUCTION}

ISO 9000 is a quality management system (hereunder abbreviated to QMS) which was first promulgated by the International Organization for Standardization (ISO) in 1987 and was introduced to Vietnam in the 1990s. According to Vietnam Productivity Center (VPC), only 13 Vietnamese companies were awarded ISO 9000 certificates in 1997, but the number rises to 184 in 2000; 612 in 2002; 2,461 in 2005; 4,282 in 2007 and over 6,000 in 2010. The upward trend of the number of enterprises using ISO 9000 indicates that the ISO 9000 QMS has more or less benefited enterprises. However, the question of whether or not this system is really effective and generates long-term benefits for enterprises still banks on effort by enterprises to maintain and improve it after certified.

In Vietnam, existing studies related to the ISO 9000 QMS have thus far revolved around impacts of the implementation of ISO 9000 on enterprises (Bùi Nguyên Hùng \& Đoàn Thị Xuân Nguyên, 2003), on the business performance of local enterprises (Phan Chí Anh, 2009), or factors impacting on satisfaction with ISO 9000 QMS by industrial companies (Hồ Thị Thúy Nga \& Hoàng Trọng Hùng, 2010), and thus there has been no research on factors affecting the efficiency of the ISO 9000 QMS in enterprises.

This paper aims to investigate influential factors and how profoundly they affect the effectiveness of the ISO 9000 QMS of HCMC-based enterprises. The remaining sections of the paper are devoted to (1) theoretical background and research model, (2) methodology and research results, and (3) discussion and recommendations.

\section{THEORETICAL BACKGROUND AND RESEARCH MODEL}

\section{a. ISO 9000:}

ISO 9000 is a quality management system promulgated by ISO in the hope of introducing common standards of a quality management system that can be widely employed by manufacturers, traders, services providers and non-profit organizations.

Up to late 2011, there have been the following members in the family of ISO 9000:

- ISO 9000:2005 (TCVN ISO 9000:2007) describes fundamentals of QMS and defines related terms.

- ISO 9001:2008 (TCVN ISO 9001:2008) specifies requirements for a QMS whereby an organization needs to demonstrate its ability to consistently provide products that meet customers and applicable statutory and regulatory requirements, and aims to enhance customer satisfaction through the effective application of the system, 
- ISO 9004:2009 provides guidance to management for achieving sustained results for all organizations in a complex, demanding, and ever changing environment.

- ISO 19011:2011 provides guidance on auditing management systems, including the principles of auditing, managing an audit program and conducting management system audits, as well as guidance on the evaluation of competence of individuals involved in the audit process, including the person managing the audit program, auditors and audit teams.

These standards of the ISO 9000 set has been adopted in Vietnam and known as TCVN ISO 9000 .

Requirements of current ISO 9000 are prescribed in ISO 9001:2008 (or TCVN ISO 9001:2008) and named ISO 9001:2008 - Quality Management System - Requirements. Once this system is employed, the organization must formulate documents, implement and maintain the quality management system, and continually improve the effectiveness of the system in accordance with requirements of ISO 9000.

\section{b. Principles of Quality Management:}

ISO 9000 is formulated on the ground of quality management principles (TCVN ISO 9000:2007).

- Customer focus: All organizations are dependent on their customers, thus it is necessary for them to comprehend and meet present and future needs of customers, and attempt to exceed their expectations.

- Leadership: Leadership is to establish the unification between purposes and goals of the organization. Leaders must build and maintain an attractive internal environment in order to enable members to achieve organization's goals.

- Participation: People of all strata are very crucial to an organization. Motivating them to participate fully in activities will utilize their capability for the organization's sake.

- Process approach: Expected results will be attainable when resources and related activities are managed as a process.

- Systemic approach to management: Identifying, comprehending and managing correlated processes as a system will generate organizational effectiveness, which in its turn will facilitate the achievement of intended goals.

- Continual improvement: Continual improvement of realized results must be a top goal of an organization. 
- Factual approach to decision making: An effective decision must be based on thorough analyses of data and information.

- Mutually beneficial relationships with suppliers: Organizations and suppliers are interdependent, and the mutually beneficial relationship will promote the competence of each party in producing added value.

\section{c. Effectiveness of the ISO 9000 QMS:}

In accordance with ISO 9000:2007, a QMS is to orient and monitor quality of an organization. Accordingly, it is a set of interrelated or interactive factors that formulate policies and goals as well as methods to achieve intended goals. Quality orientation and management includes formulation of quality policies and goals, quality planning, quality monitoring, quality assurance, and quality improvement.

In pursuant to TCVN ISO 9000:2007, the effectiveness of a QMS reflects itself in the relationship between achieved goals and employed resources. In other words, it is a relationship between goals achieved by the operation of the system and the employment of resources to run this system.

Achieved results of the QMS are reflected by the achievement of quality goals of different levels and in different departments of an organization in the long run or the short run. Resources needed for operation of the QMS are comprised of human resources, infrastructure, working environment, finance, and so on.

The formulation and operation of ISO 9000 aims to meet customer's needs with specific quality goals, while the later goals being higher than proceeding ones will motivate departments and members of an organization to try their best to achieve expected goals and thereby enhancing the performance of each department and the organization as a whole.

* Factors affecting the effectiveness of ISO 9000 quality management system: Based on quality management principles and requirements of ISO 9000, the effectiveness of a QMS banks on the following factors:

- Senior manager's commitments

By the leadership and specific actions, senior managers of an organization can set up an organization's environment in which each member is invited to operate the QMS effectively. Senior managers can employ quality management principles to implement their leadership in the QMS. 
In order to formulate and operate a QMS effectively, senior managers must be pioneers in all attempts of quality management. They must believe in the philosophy of ISO 9000, commit themselves to pursuing quality goals of the organization in the long run, instruct and take part in formulating a QMS as well as enabling all members to play an active and creative role in attaining intended goals.

- Participation of organization's members

A distinctive feature of the ISO 9000 QMS is that it must be made into documents which will be a basis to run the whole system. However, if the proactive participation of all members is not ensured, the QMS cannot operate well even if documents are perfectly formulated. Accordingly, activities as well as the operation process may be carried out by subjective opinions of operators and thus may hinder the management and cannot meet requirements. Consequently, the effectiveness of the QMS of the organization will be aggravated.

The participation of employees will highlight their role in and responsibility for observing quality management documents and extending solutions for improving such documents, which will facilitate the implementation of related activities and achievement of intended goals.

\section{- Support from suppliers}

In order to sustain the operation, an organization must utilize various resources such as materials, machinery, equipment, energy, etc. If suppliers of such resources can meet the organization's requirements in terms of quality and quantity and punctuality, it will facilitate the sustained business operation of the organization which in its turn may meet customer's needs to the maximum.

The collaboration between customers and suppliers is very crucial and plays a significant role in sustaining the operation of an enterprise and producing high quality products to meet customer's needs. Detailed information about requirements and feedbacks on product quality will enable enterprises to keep track with customer's needs and improve the quality in the hope of enhancing customer satisfaction. Additionally, reliable supply of inputs (i.e. raw materials, energy, etc.) in terms of quality, quantity, and clear origin will help enterprises stabilize their production and easily trace defected products for timely improvement.

- Advice of professional consultants 
The formulation and application of the QMS may encounter some difficulties such as a lack of objectivity when evaluating the organization's current situation and comparing its system with requirements of ISO 9000, or wasting time in orientating and implementing the stepwise formulation of the system. Therefore, advices from competent and experienced consultants will help the organization save time and resources, and quickly bring the system into practice so as to enjoy its benefits.

\section{- Quality management documents}

Quality management documents are to notify intentions and ensure the consistency in operation (TCVN ISO 9000:2007). The employment of such documents will help the organization keep track of customer's needs and timely improve products' quality, hold appropriate training courses for all members, monitor the repetition of processes and easily trace product's origin, and have objective evidence of the system operation which will serve as a basis for evaluation of the effectiveness and appropriateness of the QMS.

Each organization should identify necessary documents and media to be employed. This depends on the business size and mode, the complication of products, customer's requirements, competence of employees and the necessity of execution of the QMS. Quality management documents, if established clear-cut and reflecting the real operation of the organization, will enable employees to monitor the task quality and product quality and thereby ensuring that the QMS really works and is regularly improved.

\section{d. Measurement Scales:}

Measurement scales are established on the basis of theoretical backgrounds and qualitative preliminary research and a five-point Likert scale with 1 for absolute disagreement and 5 for absolute agreement.

"Manager's commitments" is measured by four observed variables: (1) senior managers'confidence in benefits, (2) comprehending the nature of commitments, (3) being well aware of their important role, and (4) persistently pursuing goals of the ISO 9000 quality management system.

"Role of middle managers" is measured by four observed variables namely (1) inspection, (2) close coordination in establishing the process, (3) exchanging information when implementing the process, and (4) receiving suggestions for the process improvement. 
"Participation of employees" is measured by five observed variables: (1) carrying out the task in accordance with the process, (2) being well aware of the significance of compliance with the process, (3) mastering the process related to assigned tasks, (4) extending suggestions for the process improvement, and (5) voluntarily abiding by the process.

"Internal information system" is measured by four observed variables, namely (1) the internal information system, (2) timely notification of changes in documents, (3) information regularly updated, and (4) members'easy access to necessary information about tasks.

"Collaboration of customers and suppliers" is measured by five observed variables which concentrate on: (1) customer's feedbacks about the quality of products or services, (2) ensuring the provision of quality supplies, (3) quantity, (4) adequacy of product's origin documents, and (5) provision of products/services in accordance with the company's request.

"Advice of professional consultants" is measured by four observed variables: (1) experience in implementation of the QMS, (2) thorough comprehension of the company's field, (3) mastering the QMS, and (4) good communication skills.

"Quality management documents" is measured by four observed variables: (1) appropriateness, (2) transparency and comprehensibility, (3) applicability, and (4) easy manipulation of quality management documents.

"QMS effectiveness" is measured by six observed variables, namely (1) helping the company improve the customer satisfaction, (2) appropriate use of resources, (3) reduction in wastes, (4) saving time of task implementation, (5) achievement of quality goals, and (6) the effectiveness of the ISO 9000 QMS. All measurement scales employed in the model are multidimensional.

The research model of factors affecting the effectiveness of the ISO 9000 QMS can be written as follows:

The QMS effectiveness $=\mathrm{f}($ employees, manager's commitments; middle managers, documents, professional consultants, customers and suppliers, information system)

\section{METHODOLOGY AND RESEARCH RESULTS}

\section{a. Sampling:}


In this research, the author conducts in-depth interviews with managers and employees working for enterprises wherein the ISO 9000 QMS has been applied. The survey term lasts from June 2012 till September 2012. Questionnaires are disseminated randomly to 220 respondents. Yet only 210 questionnaires are returned; and there are 204 appropriate ones which will be utilized for further analyses in SPSS. The stats indicate that:

- Position: There are 12 managers (6.4\%), 55 department heads (27\%), and 136 employees directly implementing the QMS (66.7\%).

- Seniority: Only seven people have the seniority less than a year (3.4\%), 71 respondents with the seniority from one to three years (34.8\%), and 126 respondents with the seniority larger than three years $(61.8 \%)$.

- Business field: 106 respondents have been working in the manufacturing industry (52\%), 22 ones in the trading field (10.8\%), and 76 ones in the service industry (37.3\%).

- Type of ownership: 26 respondents have been working in state-owned enterprises (12.7\%), 90 ones in joint-stock companies (40.1\%), 47 ones in limited liability companies (23\%), eight in joint-venture companies (3.9\%), and 33 in foreign-owned enterprises $(16.2 \%)$.

- Labor force: 54 enterprises employ less than 100 workers (26.5\%); 53 ones having from 100 to 300 workers (26\%); 23 ones employing 300 to 500 workers (11.3\%); and 74 ones using more than 500 workers (36.3\%).

\section{b. Analyses of Research Results:}

Testing the scales preliminarily with EFA reveals that six groups of factors are extracted at eigenvalue of 1.064 and the extracted variance of $73.47 \%$ (> 50\%). After performing EFA, there are 25 variables left in the measurement scale. Four observed variables of the "middle managers" are omitted. After the variable KHVCC 1 of "customers and suppliers" is left out, the renewed scale is named "Supplier" (NCC) due to the fact that remaining variables are related to suppliers only.

Testing the reliability of six factors with the Cronbach's Alpha coefficient indicates that all scales are reliable (i.e. the Cronbach's alpha ranging between 0.857 and 0.910 ) (see Table 1). Performing EFA at the eigenvalue of 3.920 and the extracted variance at $65.34 \%$ ( $>50 \%$ ), the measurement scale of "the QMS effectiveness" is satisfied. Testing the reliability of the scale shows that the scale is acceptable when its reliability reaches 0.893 . 
Table 1: Summary of Measurement Scale Testing Results

\begin{tabular}{lllccc}
\hline \multicolumn{1}{c}{ Concepts } & \multicolumn{1}{c}{ Factors } & N & Reliability & $\begin{array}{c}\text { Total extracted } \\
\text { variance }\end{array}$ & Evaluation \\
& Employees & 5 & 0.888 & & \\
& Manager's commitments & 4 & 0.872 & & Satisfactory \\
$\begin{array}{l}\text { Factors } \\
\text { affecting the }\end{array}$ & $\begin{array}{l}\text { Quality management } \\
\text { QMS }\end{array}$ & 4 & 0.910 & $73.4 \%$ & \\
effectiveness & Professional consultants & 4 & 0.895 & & \\
& Suppliers & 4 & 0.857 & & \\
& Information system & 4 & 0.883 & & \\
\hline The QMS efficiency & 6 & 0.893 & $65.348 \%$ & \\
\hline
\end{tabular}

Adjustment of the research model: After preliminary analyses are performed, the model is adjusted into six factors instead seven as was suggested at first (Figure 1).

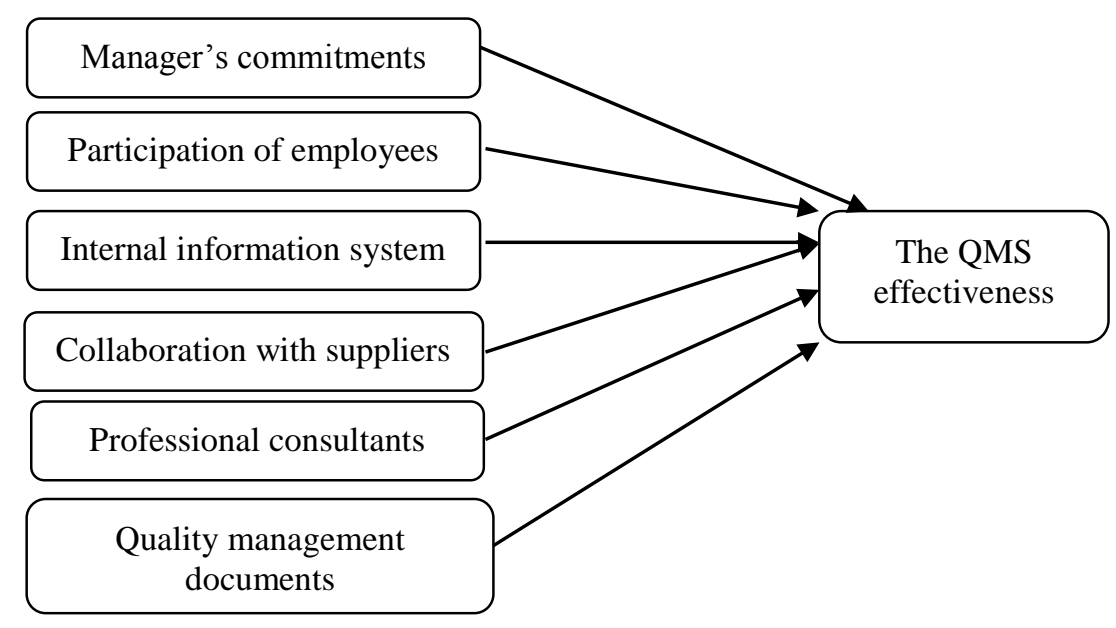

Figure 1: Adjusted Research Model of Factors Affecting the Effectiveness of the ISO 9000 QMS

The regression analysis is performed to identify factors and their influential level on the QMS effectiveness. It is assumed that the QMS effectiveness retains a linear 
relationship with the six aforementioned factors. The regression equation can be written as follows:

The QMS effectiveness $=\mathrm{a}+\mathrm{b}_{1} *$ Employees $+\mathrm{b}_{2} *$ Manager's commitments + $\mathrm{b}_{3} *$ Documents $+\mathrm{b}_{4} *$ Consultants $+\mathrm{b}_{5} *$ Consumers and suppliers $+\mathrm{b}_{6} *$ Information system $+\mathrm{e}_{\mathrm{i}}$

$b_{i}$ : The coefficient of the regression equation

$\mathrm{e}_{\mathrm{i}}$ : Residual

Since the model is built anew instead of being duplicated, the stepwise regression method is employed to explore whether independent variables are correlated with the dependent one or do exist in the regression equation. The stepwise choice of independent variables is the combination of gradual addition and gradual omission. After each step, variables in the equation will be re-examined to leave out inappropriate ones (Hoàng Trọng et al., 2008:255). Five models are obtained after analyses, and the fifth model is opted because it is supposed to be the best. The stepwise regression results are partly presented in Table 2.

Table 2: Regression Coefficient

\begin{tabular}{|c|c|c|c|c|c|c|c|c|}
\hline & \multirow{2}{*}{ Model } & \multicolumn{2}{|c|}{$\begin{array}{c}\text { Non- } \\
\text { standardized } \\
\text { coefficient }\end{array}$} & \multirow[t]{2}{*}{$\begin{array}{l}\text { Standardized } \\
\text { coefficient }\end{array}$} & \multirow{2}{*}{$\begin{array}{c}\text { t- } \\
\text { value }\end{array}$} & \multirow{2}{*}{$\begin{array}{l}\text { Sig. } \\
\text { value }\end{array}$} & \multicolumn{2}{|c|}{$\begin{array}{c}\text { Multicollinearity } \\
\text { statistics }\end{array}$} \\
\hline & & $\beta$ & $\begin{array}{l}\text { Standard } \\
\text { deviation }\end{array}$ & & & & Tolerance & VIF \\
\hline \multirow[t]{3}{*}{1} & Constant & 1.626 & 0.196 & & 8.305 & 0.000 & & \\
\hline & Documents & 0.576 & 0.051 & 0.623 & 11.306 & 0.000 & 1.000 & 1.000 \\
\hline & $\cdots$ & & & & & & & \\
\hline \multirow[t]{6}{*}{5} & Constant & 0.402 & 0.222 & & 1.813 & 0.071 & & \\
\hline & Documents & 0.228 & 0.059 & 0.246 & 3.882 & 0.000 & 0.548 & 1.823 \\
\hline & Manager's commitments & 0.202 & 0.058 & 0.223 & 3.509 & 0.001 & 0.547 & 1.828 \\
\hline & Employees & 0.198 & 0.049 & 0.222 & 4.012 & 0.000 & 0.723 & 1.382 \\
\hline & Professional consultants & 0.136 & 0.055 & 0.157 & 2.481 & 0.014 & 0.553 & 1.808 \\
\hline & Suppliers & 0.132 & 0.054 & 0.135 & 2.441 & 0.016 & 0.720 & 1.389 \\
\hline
\end{tabular}

Source: Author's calculations 
Table 2 indicates five factors affecting the QMS effectiveness (Sig. $<0.05$ and thereby statistically significant): "employees", "managers" commitments", "documents", "consultants", and "suppliers". The factor "information system" is omitted.

The regression equation can be written as follows:

The QMS effectiveness $=0.246$ documents +0.223 managers' commitmens +0.222 employees +0.157 consultants +0.135 suppliers

Testing assumptions of the regression model:

- Assumptions about a linear relationship between the dependent variable (i.e. the QMS effectiveness) and independent ones (i.e. six variables) and homoskedasticity: The chart of the relationship between the standardized predicted value and standardized residual shows that it is a linear relationship. Thus, the two assumptions are not violated.

- Assumption about the normal distribution of residual: The chart indicates that this is an approximately normal distribution (mean $\approx 0$ and the standard deviation $\approx 1$ ). Thus, this assumption is not violated.

- Assumption about lacks of correlation among independent variables: the VIF value of independent variables are smaller than 2 (Table 2), and thus no multicollinearity is found.

- Assumption about the independence of errors: The Durbin-Watson coefficient equals 1.936, and thus the assumption is not violated.

Assumption testing results prove that the regression model is appropriate.

\section{DISCUSSION OF RESEARCH FINDINGS}

The factor "quality management document" has the greatest impact on the QMS effectiveness $(B=0.246)$, which supports the theory and qualitative research results. A distinctive feature of the ISO 9000 QMS is that details must be clarified in documents which the enterprise will bank on to operate, maintain and improve its quality management system.

The influential level of "manager's commitments" on the QMS effectiveness is placed second $(B=0.223)$, which also supports the theory and qualitative research results. One of the prerequisites for the QMS effectiveness is the commitments and devotion of the enterprise's senior managers. If they do not commit themselves to the job, it implies 
that they have paid little heed to the QMS, and thus the enterprise's QMS cannot work as effectively as expected.

The third place falls to "participation of employees" $(\mathrm{B}=0.222)$. The participation of people in operation and improvement of the quality management system is a vital principle. The qualitative research indicates that no matter how well quality management documents are set up to enable employees to carry out their work best, it may be ineffective if such documents are not stringently observed during the operation. More specifically, if workers fail to abide by processes and requirements put forth in quality management documents, it might imply that they work subjectively and cannot manipulate mistakes arising out of their operation; and thus waste of resources is inevitable and intended goals may be unattainable.

With $\mathrm{B}=0.157$, "advice of professional consultants" is ranked fourth. In fact, when implementing standards of ISO 9000, enterprises often encounter difficulties in explicating standards and how to integrate them into the actual business. Without advices from professional consultants, it will take a lot of time for enterprises to comprehend standards of ISO 9000 and set up their own quality management documents.

"Collaboration of suppliers" has the least impact on the QMS effectiveness $(B=$ $0.135)$. Indeed, if enterprises are provided with raw materials, power, machinery and the like meeting their requirements of quality, quantity and time, they are able to keep their production on schedule, attain intended goals of quality and provide customers with products or services of required quality.

The internal information system does not impinge on the QMS effectiveness. As the quantitative research indicates, this factor is measured by four observed variables; yet regression analyses prove that it has no impact on the QMS effectiveness ( $p=0.102>$ 0.05 ) and thus it is omitted. Accordingly, with the employed dataset, it is impossible to conclude whether or not the internal information system has impacts on the QMS effectiveness and thus requires further researches and tests.

\section{SUGGESTIONS FOR ENTERPRISES}

Research results show that, in order to promote the effectiveness of ISO 9000 QMS, enterprises should heed quality management documents, senior managers' commitments and the participation of employees.

- In order to ensure the QMS effectiveness, the quality management documents must be established in accordance with the actual operation of the enterprise. Standards must 
be well documented, explicable and applicable. Each document should contain control information so as to ensure its availability and accessibility.

- Senior managers' commitment is a prerequisite for the successful establishment and effective utilization of a QMS. The question of whether or not a QMS could be applied and operated effectively depends heavily on the senior managers' devotion to standards of ISO 9000, their awareness of their important role in promoting the application of ISO 9000.

- Workers play a crucial role in operating and improving the QMS. Therefore, enterprises should enhance their awareness of the ISO 9000 QMS; motivate them materially and spiritually through appropriate policies so that they participate actively in the system operation; assess them on the basis of task quality and effectiveness, integrate worker's benefits with those of the enterprise; clarify their duties, obligations and rights in the organization so as to stimulate their dynamism and creativity; and provide them with sufficient resources so as to facilitate their work and achieve intended goals.

In addition to the three aforementioned factors, when opting for a consultant to support the QMS establishment, enterprises should pay attention to their competence and experience, which will reduce the time for QMS establishment and quickly bring the system into practice. When choosing suppliers, enterprises should formulate criteria (e.g. stability of quantity, quality, punctuality, etc.) to assess suppliers periodically in accordance with the enterprise's requirements; and enterprises, in their turn, are competent enough to satisfy the higher and higher need of customers.

\section{CONCLUSION}

This paper aims to investigate factors affecting the effectiveness of ISO 9000 QMS, and their influential level. The research results are significant in promoting the QMS effectiveness in enterprises and improving their business performance.

\section{LIMITATIONS AND SUGGESTIONS FOR FURTHER RESEARCH}

Measurement scales of factors (i.e. research concepts) are established after consulting HCMC-based enterprises adapting ISO 9000 (not based on the repeated model), thus the generalization of research results is limited, and further researches can cover various municipalities and provinces in Vietnam.

Samples are chosen conveniently, thus the sample's representativeness is also limited. 
The research model merely explains 55.2\% of volatility of the QMS effectiveness; the remaining $44.8 \%$ is subject to other factors. Hence, it is necessary to conduct further researches to identify those "other factors"

\section{References}

Bùi Nguyên Hùng \& Đoàn Thị Xuân Nguyên (2003), “Ảnh hưởng của việc thực hiện ISO 9000 đối với các doanh nghiệp tại TP.HCM”, Phát triển kinh tế, University of Economics HCMC.

Hoàng Trọng \& Chu Nguyễn Mộng Ngọc (2008), Phân tích dĩ liệu nghiên cúu với SPSS, Hồng Đức Publisher.

Hồ Thị Thúy Nga \& Hoàng Trọng Hùng (2010), "Các nhân tố tác động đến sự hài lòng của doanh nghiệp công nghiệp đối với hệ thống quản lý chất lượng ISO 9000”, Khoa học và Công nghệ, Vol.4(39), pp. 150-157, Đà Nẵng University.

ISO (2012), "Standards catalogue" retrieved http://www.iso.org/iso/home/store/catalogue_ics.htm.

Nguyễn Đình Thọ \& Nguyễn Thị Mai Trang (2010), Nghiên cúu khoa học trong quản trị kinh doanh, Thống kê Publisher.

Phan Chí Anh (2009), “ISO 9000 và tác động tới kết quả hoạt động doanh nghiệp VN”, retrieved from

http://vpc.org.vn/PortletBlank.aspx/DD2F3B7654B249C6A702E867DD15B8D1/View/Luandam-6-

09/ISO_9000_VA_TAC_DONG_TOI_KET_QUA_HOAT_DONG_DOANH_NGHIEP_VIET_ NAM/?print=1826528827 in July 2009.

Vietnam's Ministry of Sciences and Technology (2008), TCVN ISO 9001:2008_HTQLCL - Các yêu $c \hat{\hat{u} u}$.

Vietnam's Ministry of Sciences and Technology (2007), TCVN ISO 9000:2007_HTQLCL - Cơ sở và Tù vưng. 